\title{
Non-Cellular Component
}

National Cancer Institute

\section{Source}

National Cancer Institute. Non-Cellular Component. NCI Thesaurus. Code C125905.

A term that refers to the non-cellular component of the innate immune system which includes cytokines, chemokines, complements, and other mediators of inflammation, to the non-cellular component of blood (plasma), or the non-cellular component of body fluids and broncoalveolar lavage fluid. 